\title{
In vitro dynamic bladder models for studying urinary tract infections: a narrative review
}

\author{
Guo-Bing Xiong ${ }^{1,2} \wedge$, Sheng-Hua $\mathrm{Xie}^{2,3}$, Ai-Bo Liu ${ }^{2,4}$ \\ ${ }^{1}$ Department of Urology, Sichuan Academy of Medical Sciences \& Sichuan Provincial People's Hospital, University of Electronic Science and \\ Technology, Chengdu, China; ${ }^{2}$ Chinese Academy of Sciences Sichuan Translational Medicine Research Hospital, Chengdu, China; ${ }^{3}$ Sichuan Key \\ Laboratory of Ultrasonic Cardiac Electrophysiology and Biomechanics, Sichuan Academy of Medical Sciences \& Sichuan Provincial People's \\ Hospital, University of Electronic Science and Technology, Chengdu, China; ${ }^{4}$ Clinical Laboratory Center, Sichuan Academy of Medical Sciences \& \\ Sichuan Provincial People's Hospital, University of Electronic Science and Technology, Chengdu, China \\ Contributions: (I) Conception and design: All authors; (II) Administrative support: GB Xiong; (III) Provision of study materials or patients: All authors; \\ (IV) Collection and assembly of data: All authors; (V) Data analysis and interpretation: GB Xiong, SH Xie; (VI) Manuscript writing: All authors; (VII) \\ Final approval of manuscript: All authors. \\ Correspondence to: Guo-Bing Xiong, MD. Department of Urology, Sichuan Academy of Medical Sciences \& Sichuan Provincial People's Hospital, \\ University of Electronic Science and Technology, Chinese Academy of Sciences Sichuan Translational Medicine Research Hospital, Chengdu, China. \\ Email: xiongguobing@med.uestc.edu.cn.
}

\begin{abstract}
Experimental models of the bladder are key to studying the pathogenic mechanism of catheterrelated bacterial biofilm infection. Although numerous studies have reported multiple models, these model designs were heterogeneous. This study aimed to review the status quo and explore the problems associated with in vitro dynamic bladder models for studying urinary tract infections (UTIs). The PubMed and SinoMed databases were searched from their inception to February 2020. Studies regarding in vitro bladder models related to UTIs were reviewed based on a bibliometric evaluation of their basic characteristics and model analysis. A total of 74 papers and 44 bladder models were included in this study. The results were as follows: (I) urine transmission devices: 10 studies applied the gravity effect of culture media, while the others used peristaltic pumps, and 11 of them combined stirring or rotating forces. The flow rates in all studies ranged from $15 \mu \mathrm{L} / \mathrm{min}$ to $50 \mathrm{~mL} / \mathrm{min}$. (II) Bladder model: two studies reported on simulating the bladder using plastic bags, while the others reported on glass cylinders or fermenters with a capacity of 200 to $700 \mathrm{~mL}$. E. coli and P. mirabilis were the main bacterial strains. (III) Infection carrier: six studies reported planktonic bacteria as their infection carrier, while 45 studies reported silica gel, rubber, polyurethane, silicone, polytetrafluoroethylene, or perfusion bag. (IV) Infection medium: 25 studies reported the culture medium. Thirty-two studies reported artificial urine, while 17 studies reported human urine. (V) Research analysis: 45 studies investigated the bacterial biofilm formation in the bladder model. Thirty-six studies compared the effects of various drug coatings, diverse material surfaces, or different materials. Only five studies compared distinct bladder models. The included studies' main defects were the single simulation of bladder urodynamics, divers parameter settings, and non-standard experimental modeling. Our analysis showed for the first time that in vitro dynamic bladder models could provide new ideas for exploring the mechanism and prevention of bacterial biofilm infection in urinary implanted biomaterials. Due to the limitations of the included studies, more high-quality studies are needed to verify the conclusions above further.
\end{abstract}

Keywords: Bacterial biofilm infection; in vitro techniques; models; biological; systematic review; urinary bladder

Submitted Oct 19, 2020. Accepted for publication Jan 27, 2021.

doi: 10.21037/apm-20-2061

View this article at: http://dx.doi.org/10.21037/apm-20-2061

\footnotetext{
^ ORCID: 0000-0002-8147-5117.
} 


\section{Introduction}

Urinary tract infection (UTI) is the most common hospital-related infection, and $70-80 \%$ of these infections are associated with the use of a urethral catheter. The crucial part of UTIs' pathogenesis is the formation of bacterial biofilm on the surface of biomaterials, which can lead to refractory biofilm resistance and immune damage (1-4). In other words, the bacterial biofilm is considered the key to biomaterial-related infections, although its mechanism of formation is still unclear (5). The discovery of mechanisms for the prevention and control of biofilm infection has become the primary research hotspot. In recent years, the study of biofilm infection from the perspective of fluid mechanical biology provided a new research direction. Numerous studies have been conducted on static planktonic bacteria. However, the materials for urinary tract implantation relating to the biofilm bacterial infection are exposed to a complex dynamic urinary flow environment. From the perspective of mechanical biology, organisms are affected by the mechanical environment since mechanical factors act on the entire body and organs' biological processes, including positive functional adaptation reconstruction, negative structural damage, and disease occurrence. At present, a variety of successful bacterial biofilm models have been reported. As far as in vitro research is concerned, the design of experimental models that closely reflect actual human bladder urodynamic conditions is key to studying the pathogenic mechanism of catheter-related bacterial biofilm infection, and a new anti-biofilm infection technology is required. However, previous studies' bladder models differed in their ability to simulate human urinary flow effectively. In particular, the hydrodynamics status and standardization were inconsistent.

This review systematically evaluated the current research status and investigated the problems associated with in vitro dynamic bladder models for studying UTIs. We strongly believe that this research can provide a valuable reference for constructing in vitro models of UTIs. This study may also offer some insight into the mechanism and prevention of catheter-related complicated UTIs. We present the following article following the Narrative review checklist (available at http://dx.doi. org/10.21037/apm-20-2061).

\section{Methods}

\section{Research selection}

\section{Inclusion and exclusion criteria}

All previous studies that were based on an in vitro bladder model related to human UTI were included in this review. The selected research articles varied in the study's model and design, and language preference was given to studies published in Chinese and English only. Studies with incomplete data, repeated publications, in vivo animal experiments and human studies, and those without a bladder model as the research topic were excluded from this study.

\section{Literature retrieval}

The PubMed and SinoMed databases were electronically searched from the date of inception of the database to February 2020. The references of relevant studies were also searched. Free words were used for retrieval; for example, in vitro, ex vivo, bladder, and model.

\section{Literature evaluation and analysis}

Literature selection was conducted by reading the articles' titles and abstracts, and unrelated articles were excluded. Furthermore, the full texts of the articles were thoroughly checked to determine the relevance of the research. Inconsistencies were resolved by negotiation. At present, there is no authoritative quality evaluation tool for in vitro research (6-9), although some scholars suggest the OHAT risk-of-bias tool and Toxicological data reliability assessment tool (ToxRTool) (10-12). However, these methods are mainly used to evaluate the quality of animal research, and therefore, were unfit for the present research purpose. For this reason, a quality assessment of the included studies was not performed. The selected articles were classified and analyzed according to bibliometrics analysis, bladder model, model bacteria, infection medium, and carrier.

\section{Discussion}

\section{Basic characteristics of included studies}

We obtained 1,850 articles (1,776 in English and 174 in Chinese) and 22 references. Two reviewers (GuoBing Xiong and Ai-Bo Liu) independently read the titles 
and abstracts of the studies. In total, 120 articles [112 in English (including 22 references), two in Japanese, and six in Chinese] were included in the preliminary screening. Finally, 74 articles published in English, including 14 articles obtained by searching the reference lists of relevant articles were included in this study. The basic characteristics of the 74 articles are summarized in https://cdn.amegroups. cn/static/public/apm-20-2061-1.pdf. The selected 74 studies were published between 1966 and 2020, and the decade distribution of studies as follow: 23 studies reported 2011-2020 (13-35), 10 studies reported 2001-2010 (36-45), 17 studies reported 1991-2000 (46-62), 10 studies reported 1981-1990 (63-72), 13 studies reported 1971-1980 (73-85), only one study reported $<1971$ (86).

\section{Model construction and analysis}

According to the human urinary bladder and urine flow, i.e., continuous urine secretion, one-way flow from the kidney, ureter, and bladder to the urethra, cyclical bladder urine storage, and intermittent urination, we summarized the key components of the models into four categories. These included the devices for bacterial culture medium storage and collection of waste liquid, the power devices for urinary flow transmission (gravity, pump, combined agitation, or rotation to the latter), bladder models (combined with infection carrier), and the input and output pathways of the culture medium. All of the equipment was assembled to simulate the human urinary bladder system.

Some of the selected literature established in vitro bladder models based on the same models or with some modifications [two bladder models $(13,15)$ were modified from the model reported by Abbott et al. (21); eight bladder models $(16,17,19,30,32,33,35,38)$ were modified from the model reported by Stickler et al. (49); two bladder models $(32,39)$ were modified from the model reported by Gaonkar et al. (43); one bladder model (28) was modified from the model reported by Fu et al. (36); two bladder models $(31,34)$ was modified from the model reported by Andersen et al. (37); one bladder model (45) was modified from the model reported by Stickler et al. (55); one bladder model (48) was modified from the model reported by Getliffe et al. (59); six bladder models (19,41,50-53) were modified from the model reported by Stickler et al. (58); one bladder model (62) was modified from the model reported by Stickler et al. (64); 11 bladder models $(63,65-70,72,73,75,76)$ were modified from the model reported by Greenwood et al. (77); one bladder model (75) was modified from the model reported by Greenwood et al. (78); seven bladder models (79-85) were modified from the model reported by O'Grady et al. (86)]. Hence, among the 74 studies, a total of 44 in vitro bladder models were finally included.

\section{Components of the model and its analysis}

\section{The power devices of urinary flow}

Ten studies $(14,22,39,42,43,50,51,53,56,74)$ used the culture medium's gravity, while the others applied peristaltic pumps to exert power for fluid transmission. Of these, 11 studies $(13,21-23,44,68,69,72,78,85,86)$ were combined with stirring or rotating instruments and were set to a certain flow rate $(15 \mu \mathrm{L} / \mathrm{min}$ to $50 \mathrm{~mL} / \mathrm{min})$. Meanwhile, 18 studies $(13,15,16,21,23,24,30,53,57,60,61,68,69,70-73,75)$ established the parameters of residual urine and micturition to simulate the clinical physiology or pathological urination and urine retention, so that the urine flow modes of the models more closely reflected the unsteady flow stress conditions of human bladder urine environments.

We have summarized the power apparatuses of urinary flow in the selected bladder models on human urinary flow's anatomy and physiology, which were the key technologies used to construct the models. These involved the pump, fluid gravity, or incorporated stirring or rotating devices into the models to provide urine transmission and urination power.

\section{Bladder model}

Only two studies $(14,42)$ simulated the bladder using plastic bags, while the remaining studies used glass bottles or cylinders with a heterogeneous capacity of 200 to $700 \mathrm{~mL}$. From a biomechanical standpoint, bladder tissue's elemental mechanical properties include elasticity, viscoelasticity, and plastic deformations $(87,88)$. As a soft biological shell, the human bladder is considered to be a viscoelastic material in biomechanics; the flow pattern of the urine in the bladder is neither a static model nor a simple laminar model, importantly the latter one which is often neglected in the past (89-92). Therefore, it has been suggested that the design of experimental simulated bladders models should be further improved based on existing technologies and crafts. In particular, under the premise of a lack of ideal materials for bladder stimulation, the hydrodynamic design of urinary flow should simulate the unsteady flow stress conditions (turbulent stress) as much as possible (93). Moreover, the bladder's capacity should be standardized; either equal to 
the physiological capacity of the human bladder or reduced according to a specific proportion so that it can work with the enhanced mechanical-biological features of the dynamic bladder urine environment.

\section{Infection carrier}

E. coli and P. mirabilis were the main typical strains for infection research, with a suitable consistency and the clinical isolation strains of catheter-related to UTI. Such refractory infections are complicated by the unique ability of $P$. mirabilis to form crystalline biofilms based on their crystalline nature owing to ureolytic biomineralization, eventually leading to encrusted and blocked implanted biomedical devices. This is especially important for indwelling urethral catheters and ureteral stents during daily clinical practice $(94,95)$.

\section{Infection vectors}

Sixty-seven studies reported the infection vectors, including infected urine (64), rubber (76), planktonic bacteria $(21,77)$, polymer $(42,46)$ with the former polyolefin copolymer, glass $(23,31)$ with the former sponge simultaneously, polyurethane $(19,20,44,45)$, latex $(39,43,50,58,60)$, Foley catheter $(22,47,48,53,56,59)$ with no statement of the specific materials, agar plates $(13,15,57,62,65,68,70,71,73)$, and silicone $(14,16-18,24-$ $30,32,33-38,40,41,49,51,52,54,55)$. The other eight studies $(20,23,31,43-45,58,60)$ also reported some materials, while the remaining 17 studies $(61,63,65,67,69,72,74,75,78-86)$ did not explicitly report infection vectors.

At present, most of the urinary catheters and stents used in urological practice are made up of silica gel and polyurethane. Some differences existed in the included studies, and thus, it is suggested that future research should focus on these two kinds of medical biomaterials. It is particularly emphasized that the initial bacterial adhesion of bacterial biofilms is mediated by multiple factors, among which the properties of biomaterials participate in the entire biofilm formation process, especially the physicochemical mechanism. They are involved in early bacterial adhesion and in the late stages of what is called "surface-programmed" biofilm growth, which is another important research direction to pursue (96-98).

\section{Infection media}

The culture medium also played an important role. Twenty-five studies reported different culture mediums, such as tryptone liquid culture (36) and MHB culture medium (13-15,21,56,61,63,66-72,74,75,77-84). Meanwhile, 17 studies reported human urine $(20,24,25,28,29,33,46,48,49,57,58,61,65,71-73,76)$, and the remaining 32 studies reported artificial urine. Undoubtedly, urine that could be used as a culture medium is the closest simulation of the human environment. Although studies have been carried out using an artificial urine formula, the standardized protocol for artificial urine or the urine of healthy volunteers, especially the latter's homogeneity problem, remains to be further explored (99).

\section{Research design and content analysis}

Forty-five studies were conducted to explore bacterial biofilm formation in bladder models, which corresponds with the current research focus. A total of 36 studies were performed with comparative experimental designs, mainly consisting of comparisons between various coatings of drugs or different materials, including between static and dynamic models in three studies $(20,27,30)$, the comparative analysis of culture fluids in two studies $(56,57)$, comparisons between multiple interventions in 21 studies $(13,14,17-20,22$, 28-30,36,38,39,41,43,50,53-55,58,64), comparisons between infection vectors in eight studies $(37,40,42,44,45,52,53,58)$, and comparisons between experimental temperature in one study (37).

There were two primary categories of interventions; antibiotics and drug coating. (I) Antibiotic interventions included the following: antibacterial phage $(28,36)$, norfloxacin and nano silver ion (20), lavage antibacterial solution (14,22), fosfomycin (13), E. coli lysatesIAA (urease inhibitor)-allicin (17), biodegradable aqueous polyurethane polymer with ciprofloxacin and streptomycin (19), single agent or double or triple combinations of $1 \%$ polygalacturonic acid, $0.4 \%$ octanoic acid and $0.3 \%$ hydrogen peroxide (22), connecting a $9 \mathrm{~V}$ direct current line containing silver (41), Jack Bean urease of acid bladder irrigation solution $(20 \mathrm{mg}$ urease plus $1 \mathrm{~L}$ urine), different bladder irrigators (UroTainer, Bladder Syringe, Optiflow, $1 \%$ hydrochloric acid) (48), bladder irrigation solution $(0.9 \%$ normal saline, sulpir G, 1\% mandelic acid) (59), various concentrations of urease inhibitor, acetohydroxamic acid or fluoroimide (51), drainage systems mono flo, S4, P4, pp2000n, and sustained-release device embedded silver ion (55), $4 \mathrm{~mA}$ Iontophoresis-gentamicin (57), and chlorhexidine (64). (II) Drug coatings included the following: silver coating (50), polytetrafluoroethylene silver nanocomposite coating (18), 
ciprofloxacin coating (58), chlorhexidine-sulfadiazine silver/chlorhexidine-silver sulfadiazine-triclosan coating/ silver hydrogel-nitrofurazone coating (43), nitrofurazone/ triclosan impregnation (39), silver hydrogel/antimicrobial peptide coating (24), minocycline-rifampicin coating (29), and acylase coating of QS destructing enzyme (30), and triclosan $(0 \%$ vs. $0.5 \%, 1 \%, 4 \%)$ coating/pure solventhydrogel coating/hydrogel, and iodized or hydrogel plus polyhexamethylene biguanide (PHMB) coating (38).

From this, it is clear that there is obvious diversity in research. On the one hand, it implies that the problem of anti-infection, especially biofilm infection, is serious, and also suggests that the efficacy, safety, and cost of existing interventions should be summarized promptly to provide a reference for the future development of safe and effective coated medical implants with wide adaptability.

In total, only five studies reported a comparative experiment of in vitro bladder models $(20,27,30,56,57)$, which are summarized in Table S1. Among these, Frant et al. (20) suggested that biofilm formation was more prevalent in the BioEncrustation dynamic bladder model and that more substances were observed in the urine scale. Meanwhile, Rasmussen et al. (56) suggested that bacterial infection increased, and retrograde infection was found to be more prevalent in the bladder model group without a urine meter. These two studies demonstrated the value of a dynamic bladder model for the mediation of bacterial infection. The small number of studies involving direct comparison experiments with different bladder models is a particular regret of the present study. However, we can summarize meaningful results from the different design techniques of urine transport pattern and force in existing bladder models.

Moreover, the principle of hydrodynamics is applied for a random movement of bladder urine flow. The intracavity indwelling catheter tip and water bag's characteristics are to create a unique stress environment of unsteady flow, i.e., turbulent shear stress, which can be formed in the body when the catheter is indwelled in the bladder. Therefore, the question arises about the formation of bacterial biofilm models simulating human bladder urine flow $(100,101)$. There are complexities and difficulties in the construction of an in vitro bladder model. Despite the significant advancements that have been reported in numerous related articles regarding the 44 bladder models included in this study, the design and craft remain unclear and technical limitations still exist. Most published studies have only emphasized the simple movement of fluid by gravity or the unidirectional constant flow under the effect of an electric pump, etc. However, they have failed to consider the following situations comprehensively: the effect of the viscoelastic properties of the bladder, the consequence of the indwelling urinary catheter, the occurrence of urine retention phenomenon, as well as the volume of urine transformation, urination flow rate, residual urine, periodic gradual urine filling, and short-term micturition. In practice, the real state of human urinary flow is turbulent shear stress, as discussed above, yet this concept and its compound stress environment have not been fully simulated (89-93). The existing model design ideas are relatively simple, but the design technology and modules are not standardized (102).

Henceforth, we aim to systematically review the main components and key construction technologies of the in vitro bladder models in existing studies and examine their defects to overcome difficulties in constructing in vitro bladder models and improve their performance for studying urinary biomaterial infection. This will help provide a worthwhile reference for bladder model construction that closely reflects the actual bladder urine flow conditions. The direct comparison of the bladder models was only reported in five studies; hence, more verification of the bladder model performance is needed. We can ensure the subsequent studies' authenticity only when the scientific feasibility and repeatability of the experimental model can be fully confirmed. This review could provide new research directions and translate basic research achievements into clinical practice.

There are some limitations in this study that should be noted. Firstly, the bladder models of the included studies were not standardized, some research details were unclear, the technical case-based designed schemes lacked a set of standards, and the evaluation indexes were multifarious. This made it difficult to compare the results of various studies and multiple bladder models, and thus, it could only be summarized and analyzed according to the existing data through simple quantitative and qualitative analysis. Secondly, the simulation and further verification of the real stress conditions and even the compound stresses of the bladder urine flow have not yet been reported. Importantly, the in vitro models lack the characterizations of bladder tissue architecture and the host stress responses, and therefore cannot provide a sufficient reference. Thirdly, a quantitative meta-analysis was not available due to the lack of homogeneity between the research data. Furthermore, quality evaluation of the in vitro research could not be performed. Lastly, literature retrieval was limited to articles 
published in English and Chinese from the PubMed and SinoMed databases, respectively; thus, selection bias was difficult to avoid.

\section{Conclusions}

To our knowledge, this is the first systematic review of in vitro dynamic bladder models for studying UTIs. In conclusion, the existing research suggests that the in vitro bladder model can provide new ideas for exploring the pathogenic mechanisms, prevention, and control of bacterial biofilm infections related to bio-implants. Nevertheless, based on the principles of fluid and viscoelastic biomechanics and mechanical biology, model designs should focus on simulating the complex stress environment of the actual bladder urine flow, combined with the construction of a bacterial biofilm generation carrier, culture medium, standardization of the bladder model, as well as verification of the scientific feasibility and repeatability of the model. At present, we are investigating the effect of in vitro urine turbulent shear stress of the bladder model on the formation of bacterial biofilm in the hope of obtaining some meaningful results (103).

\section{Acknowledgments}

Funding: This work was supported by the National Natural Science Foundation of P.R. China (Grant No. 31600759) and by the Doctor Foundation of Sichuan Academy of Medical Sciences \& Sichuan People's Hospital (Grant No. 2015BS01).

\section{Footnote}

Reporting Checklist: The authors have completed the Narrative review checklist. Available at http://dx.doi. org/10.21037/apm-20-2061

Conflicts of Interest: All authors have completed the ICMJE uniform disclosure form (available at http://dx.doi. org/10.21037/apm-20-2061). The authors have no conflicts of interest to declare.

Ethical Statement: The authors are accountable for all aspects of the work in ensuring that questions related to the accuracy or integrity of any part of the work are appropriately investigated and resolved.
Open Access Statement: This is an Open Access article distributed in accordance with the Creative Commons Attribution-NonCommercial-NoDerivs 4.0 International License (CC BY-NC-ND 4.0), which permits the noncommercial replication and distribution of the article with the strict proviso that no changes or edits are made and the original work is properly cited (including links to both the formal publication through the relevant DOI and the license). See: https://creativecommons.org/licenses/by-nc-nd/4.0/.

\section{References}

1. Clarke K, Hall CL, Wiley Z, et al. Catheter-associated urinary tract infections in adults: diagnosis, treatment, and prevention. J Hosp Med 2020;15:552-6.

2. Weber DJ, Sickbert-Bennett EE, Gould CV, et al. Incidence of catheter-associated and non-catheterassociated urinary tract infections in a healthcare system. Infect Control Hosp Epidemiol 2011;32:822-3.

3. Srivastava S, Bhargava A. Biofilms and human health. Biotechnol Lett 2016;38:1-22.

4. Römling U, Balsalobre C. Biofilm Infections, Their resilience to therapy and innovative treatment strategies. J Intern Med 2012;272:541-61.

5. Vestby LK, Grønseth T, Simm R, et al. Bacterial biofilm and its role in the pathogenesis of disease. Antibiotics (Basel) 2020;9:59.

6. Xiong GB, Qiu MX. Chapter IV research/evidence quality assessment. In: Zhang T, Zhong W, Li B. editors. Practical Evidence-Based Medicine Methodology, 2nd ed., Central South University Press, Wuhan, 2014:95-227.

7. Zeng X, Zhang YG, Kwong JS, et al. The methodological quality assessment tools for preclinical and clinical studies, systematic review and meta-analysis, and clinical practice guideline: a systematic review. J Evid Based Med 2015;8:2-10.

8. Lynch HN, Goodman JE, Tabony JA, et al. Systematic comparison of study quality criteria. Regul Toxicol Pharmacol 2016;76:187-98.

9. Elshafay A, Omran ES, Abdelkhalek M, et al. Reporting quality in systematic reviews of in vitro studies: a systematic review. Curr. Med Res Opin 2019;35:1631-41.

10. Assessing risk of bias. Available online: https://www.nhmrc. gov.au/guidelinesforguidelines/develop/assessing-risk-bias, 2020 (accessed 1 June 2020).

11. OHAT Risk of Bias Rating Tool for Human and Animal Studies. Available online: https://ntp.niehs.nih.gov/ntp/ 
ohat/pubs/riskofbiastool_508.pdf, 2020 (accessed 1 June 2020).

12. Schneider K, Schwarz M, Burkholder I, et al."ToxRTool", a new tool to assess the reliability of toxicol.ogical data. Toxicol Lett 2009; 189:138-44.

13. Abbott IJ, van Gorp E, Wijma RA, et al. Oral Fosfomycin Efficacy with Variable Urinary Exposures following Single and Multiple Doses against Enterobacterales: the Importance of Heteroresistance for Growth Outcome. Antimicrob Agents Chemother 2020;64:e01982-19.

14. Vargas-Cruz N, Rosenblatt J, Reitzel RA, et al. Pilot ex vivo and in vitro evaluation of a novel foley catheter with antimicrobial periurethral irrigation for prevention of extraluminal biofilm colonization leading to catheterassociated urinary tract infections (CAUTIs). Biomed Res Int 2019;2019:2869039.

15. Abbott IJ, Dekker J, van Gorp E, et al. Impact of bacterial species and baseline resistance on fosfomycin efficacy in urinary tract infections. J Antimicrob Chemother 2020;75:988-96.

16. Nzakizwanayo J, Pelling H, Milo S, et al. An in vitro bladder model for studying catheter-associated urinary tract infection and associated analysis of biofilms. Methods Mol Biol 2019;2021:139-58.

17. Imani Rad H, Peeri H, Amani M, et al. Allicin prevents the formation of Proteus-induced urinary crystals and the blockage of catheter in a bladder model in vitro. Microb Pathog 2019;132:293-301.

18. Wang L, Zhang S, Keatch R, et al. In-vitro antibacterial and anti-encrustation performance of silverpolytetrafluoroethylene nanocomposite coated urinary catheters. J Hosp Infect 2019;103:55-63.

19. Xu Y, Wang J, Hao Z, et al. Biodegradable ciprofloxacinincorporated waterborne polyurethane pol.ymers prevent bacterial biofilm formation in vitro. Exp Ther Med 2019;17:1831-6.

20. Frant M. Dayyoub E, Bakowsky U, et al. Evaluation of a ureteral catheter coating by means of a BioEncrustation in vitro model. Int J Pharm 2018;546:86-96.

21. Abbott IJ, Meletiadis J, Belghanch I, et al. Fosfomycin efficacy and emergence of resistance among Enterobacteriaceae in an in vitro dynamic bladder infection model. J Antimicrob Chemother 2018;73:709-19.

22. Rosenblatt J, Reitzel R, Vargas-Cruz N, et al. Foley catheter with peri-urethral antimicrobial irrigation for the prevention of catheter associated urinary tract infections - assessment in an model. Open Forum Infect Dis
2017;4:S481.

23. Hobbs T, Schultz LN, Lauchnor EG, et al. Evaluation of biofilm induced urinary infection stone formation in a novel laboratory model system. J Urol 2018;199:178-85.

24. Chua RYR, Lim K, Leong SSJ, et al. An in-vitro urinary catheterization model that approximates clinical conditions for evaluation of innovations to prevent catheter-associated urinary tract infections. J Hosp Infect 2017;97:66-73.

25. Maierl M, Jörger $M$, Rosker $P$, et al. In vitro Dynamic Model of a Catheterized Bladder and Biofilm Assay. Bio Protoc 2015;5:e1381.

26. Milo S, Thet NT, Liu D, et al. An in-situ infection detection sensor coating for urinary catheters. Biosens Bioelectron 2016;81:166-72.

27. Azevedo AS, Almeida C, Gomes LC, et al. An in vitro model of catheter-associated urinary tract infections to investigate the role of uncommon bacteria on the Escherichia coli microbial consortium. Biochemical Engineering Journal 2017;118:64-9.

28. Lehman SM, Donlan RM. Bacteriophage-mediated control of a two-species biofilm formed by microorganisms causing catheter-associated urinary tract infections in an in vitro urinary catheter model. Antimicrob Agents Chemother 2015;59:1127-37.

29. Salvarci A, Koroglu M, Gurpinar T. Evaluation of antimicrobial activities of minocycline and rifampinimpregnated silicone surfaces in an in vitro urinary system model. J Pak Med Assoc 2015;65:115-9.

30. Ivanova K, Fernandes MM, Mendoza E, et al. Enzyme multilayer coatings inhibit Pseudomonas aeruginosa biofilm formation on urinary catheters. Appl Microbiol Biotechnol 2015;99:4373-85.

31. Klein K, Palarasah Y, Kolmos HJ, et al. Quantification of filamentation by uropathogenic Escherichia coli during experimental bladder cell infection by using semi-automated image analysis. J Microbiol Methods 2015;109:110-6.

32. Holling N, Lednor D, Tsang S, et al. Elucidating the genetic basis of crystalline biofilm formation in Proteus mirabilis. Infect Immun 2014;82:1616-26.

33. Reisner A, Maierl M, Jörger M, et al. Type 1 fimbriae contribute to catheter-associated urinary tract infections caused by Escherichia coli. J Bacteriol 2014;196:931-9.

34. Andersen TE, Khandige S, Madelung M, et al. Escherichia coli uropathogenesis in vitro: invasion, cellular escape, and secondary infection analyzed in a human bladder cell infection model. Infect Immun 2012;80:1858-67.

35. Malic S, Waters MG, Basil L, et al. Development of 
an "early warning" sensor for encrustation of urinary catheters following Proteus infection. J Biomed Mater Res B Appl Biomater 2012;100:133-7.

36. Fu W, Forster T, Mayer O, et al. Bacteriophage cocktail for the prevention of biofilm formation by pseudomonas aeruginosa on catheters in an in vitro model system. Antimicrob Agents Chemother 2010;54:397-404.

37. Andersen TE, Kingshott P, Palarasah Y, et al. A flow chamber assay for quantitative evaluation of bacterial surface colonization used to investigate the influence of temperature and surface hydrophilicity on the biofilm forming capacity of uropathogenic Escherichia coli. J Microbiol Methods 2010;81:135-40.

38. Kazmierska KA, Thompson R, Morris N, et al. In vitro multicompartmental bladder model for assessing blockage of urinary catheters: effect of hydrogel coating on dynamics of Proteus mirabilis growth. Urology 2010;76:515.e15-20.

39. Williams GJ, Stickler DJ. Some observations on the migration of proteus mirabilis and other urinary tract pathogens over foley catheters. Infect Control Hosp Epidemiol 2008;29:443-5.

40. Barford JM, Anson K, Hu Y, et al. A model of catheter-associated urinary tract infection initiated by bacterial contamination of the catheter tip. BJU Int 2008;102:67-74.

41. Chakravarti A, Gangodawila S, Long MJ, et al. An electrified catheter to resist encrustation by Proteus mirabilis biofilm. J Urol 2005;174:1129-32.

42. Jones DS, Djokic J, Gorman SP. Characterization and optimization of experimental variables within a reproducible bladder encrustation model and in vitro evaluation of the efficacy of urease inhibitors for the prevention of medical device-related encrustation. J Biomed Mater Res B Appl Biomater 2006;76:1-77.

43. Gaonkar TA, Sampath LA, Modak SM. Evaluation of the antimicrobial efficacy of urinary catheters impregnated with antiseptics in an in vitro urinary tract model. Infect Control Hosp Epidemiol 2003;24:506-13.

44. Gorman SP, Garvin CP, Quigley F, et al. Design and validation of a dynamic flow model simulating encrustation of biomaterials in the urinary tract. J Pharm Pharmacol 2003;55:461-8.

45. Park JH, Cho YW, Kwon IC, et al. Assessment of PEO/ PTMO multiblock copolymer/segmented polyurethane blends as coating materials for urinary catheters: in vitro bacterial adhesion and encrustation behavior. Biomaterials 2002;23:3991-4000.

46. Choong SK, Wood S, Whitfield HN. A model to quantify encrustation on ureteric stents, urethral catheters and polymers intended for urological use. BJU Int 2000;86:414-21.

47. Takahashi S, Ebisu H, Hirose T, et al. Bactericidal activity of gatifloxacin (AM-1155) against Pseudomonas aeruginosa and Enterococcus faecalis in an in vitro bladder model simulating human urinary concentrations after oral administration. Chemotherapy 2000;46:122-8.

48. Getliffe KA, Hughes SC, Le Claire M. The dissolution of urinary catheter encrustation. BJU Int 2000;85:60-4.

49. Stickler DJ, Morris NS, Winters C. Simple Physical Model to Study Formation and Physiology of Biofilms on Urethral Catheters. Methods Enzymol 1999;310:494-501.

50. Morris NS, Stickler DJ. Encrustation of indwelling urethral catheters by Proteus mirabilis biofilms growing in human urine. J Hosp Infect 1998;39:227-34.

51. Morris NS, Stickler DJ. The effect of urease inhibitors on the encrustation of urethral catheters. Urol Res 1998;26:275-9.

52. Stickler DJ, Morris NS, McLean RJ, et al. Biofilms on indwelling urethral catheters produce quorum-sensing signal molecules in situ and in vitro. Appl Environ Microbiol 1998;64:3486-90.

53. Morris NS, Stickler DJ, Winters C. Which indwelling urethral catheters resist encrustation by proteus mirabilis biofilms? Br J Urol 1997;80:58-63.

54. Darouiche RO, Safar H, Raad II. In vitro efficacy of antimicrobial-coated bladder catheters in inhibiting bacterial migration along catheter surface. J Infect Dis 1997;176:1109-12.

55. Stickler DJ, Morris NS, Williams TJ. An assessment of the ability of a silver-releasing device to prevent bacterial contamination of urethral catheter drainage systems. Br J Urol 1996;78:579-88.

56. Rasmussen A, Frimodt-Møller N, Espersen F, et al. Retrograde contamination and practical handling of urinemeters: a comparison of three systems for the measurement of hourly diuresis in an experimental bladder-drainage model and in clinical use. Br J Urol 1996;78:187-91.

57. Wong HY, Riedl CR, Griffith DP. The effect of iontophoresis on bacterial growth in urine. J Urol 1995;154:1944-7.

58. Stickler DJ, Howe NS, Winters C. Bacterial biofilm growth on ciprofloxacin treated urethral catheters. Cells Mater 1994;4:387-98.

59. Getliffe KA. The use of bladder wash-outs to reduce urinary catheter encrustation. Br J Urol 1994;73:696-700.

60. Schmitz W, Nolde A, Marklein G, et al. In Vitro studies 
of encrustations on catheters, a model of infection stone formation. Cells and Materials 1993;3:1-10.

61. Mulhall A. Development of an in vitro bladder model. Nurs Stand 1992;7:35-7.

62. King JB, Stickler DJ. The effect of repeated instillations of antiseptics on catheter-associated urinary tract infections: a study in a physical model of the catheterized bladder. Urol Res 1992;20:403-7.

63. Muranaka K, Greenwood D. The response of Streptococcus faecalis to ciprofloxacin, norfloxacin and enoxacin. J Antimicrob Chemother 1988;21:545-54.

64. Stickler DJ, Clayton CL, Chawla JC. The resistance of urinary tract pathogens to chlorhexidine bladder washouts. J Hosp Infect 1987;10:28-39.

65. Pinasi C, Albini E, Marca G. Correlation between bactericidal activity of fosfomycin trometamol in an in vitro model of the urinary bladder and susceptibility testing. Eur Urol 1987;13:80-5.

66. Greenwood D. Activity of the trometamol salt of fosfomycin in an in vitro model of the treatment of bacterial cystitis. Infection 1986;14:186-9.

67. Greenwood D. An in-vitro model simulating the hydrokinetic aspects of the treatment of bacterial cystitis. Antimicrob Chemother 1985;15 Suppl A:103-9.

68. Greenwood D, Baxter S, Cowlishaw A, et al. Antibacterial activity of ciprofloxacin in conventional tests and in a model of bacterial cystitis. Eur J Clin Microbiol 1984;3:351-4.

69. Greenwood D. The assessment of antimicrobial activity in an in-vitro model of the treatment of bacterial cystitis. J Antimicrob Chemother 1984;13:43-8.

70. Greenwood D, Osman M, Goodwin J, et al. Norfloxacin: activity against urinary tract pathogens and factors influencing the emergence of resistance. J Antimicrob Chemother 1984;13:315-23.

71. Anderson JD, Eftekhar F. Study of the enhancement of beta-lactam activity by amdinocillin in a model of the human urinary bladder. Am J Med 1983;75:42-7.

72. Greenwood D, Slack RC. The antibacterial activity of hexamine (methenamine), hexamine hippurate and hexamine mandelate. Infection 1981;9:223-7.

73. Anderson JD, Johnson KR, Aird MY. Comparison of amoxicillin and ampicillin activities in a continuous culture model of the human urinary bladder. Antimicrob Agents Chemother 1980;17:554-7.

74. Greenwood D, Kawada Y, O'Grady F. An in vitro model for assessing optimum antibiotic dosage in urinary tract infection. Infection 1980;Suppl 1:35-8.
75. Kawada Y, Greenwood D, O'Grady F. Response of escherichia coli to beta-lactam antibiotics: effect of the concomitant presence of staphylococci exhibiting inducible Beta-lactamase activity. Infection 1980;8:81-5.

76. Anderson JD, Eftekhar F, Aird MY, et al. Role of bacterial growth rates in the epidemiology and pathogenesis of urinary infections in women. J Clin Microbiol 1979;10:766-71.

77. Greenwood D, O'Grady F. An in vitro model of the urinary bladder. J Antimicrob Chemother 1978;4:113-20.

78. Greenwood D, O'Grady F. Is your dosage really necessary? Antibiotic dosage in urinary infection. Br Med J 1977;2:665-7.

79. Greenwood D, O'Grady F. The activity of polymyxins against Escherichia coli in an in-vitro model of the urinary bladder. J Med Microbiol 1977;10:255-9.

80. Greenwood D, O'Grady F. Factors influencing the response of Escherichia coli to antibiotics in conditions prevailing in the infected urinary bladder. Br J Exp Pathol 1976;57:303-9.

81. Greenwood D, O'Grady F. Activity and interaction of trimethoprim and sulphamethoxazole against Escherichia coli. J Clin Pathol 1976;29:162-6.

82. Greenwood D, O'Grady F. Response of ampicillin resistant Escherichia coli to cephalosporins in an in vitro model simulating conditions of bacterial growth in the urinary bladder. Br J Exp Pathol 1975;56:167-71.

83. Greenwood D, Chan-Teoh CH, O'Grady F. Activity of cefazolin against dense populations of enterobacteria. Antimicrob Agents Chemother 1975;7:191-5.

84. Greenwood D, O'Grady F. Potent combinations of betalactam antibiotics using the beta-lactamase inhibition principle. Chemotherapy 1975;21:330-41.

85. O'Grady F, Mackintosh IP, Greenwood D, et al. Treatment of "bacterial cystitis" in fully automatic machanical models simulating conditions of bacterial growth in the urinary bladder. Br J Exp Pathol 1973;54:283-90.

86. O'Grady F, Pennington JH. Bacterial growth in an in vitro system simulating conditions in the urinary bladder. Br J Exp Pathol 1966;47:152-7.

87. Damaser MS. Whole bladder mechanics during filling. Scand J Urol Nephrol Suppl 1999;201:51-8; discussion 76-102.

88. Ajalloueian F, Lemon G, Hilborn J, et al. Bladder biomechanics and the use of scaffolds for regenerative medicine in the urinary bladder. Nat Rev Urol 2018;15:155-74.

89. Arnold SJ. Disturbed urinary flow: urethral dynamics. 
JAMA 1967;201:274-5.

90. The function and contrast filling of the urethra from the standpoint of physics: flow conditions in the normal urethra during micturition. Acta Radiologica 1952;38:13-33.

91. Martinez-Borges AR. Turbulent urinary flow in the urethra could be a causal factor for benign prostatic hyperplasia. Med Hypotheses 2006;67:871-5.

92. Chapter 10 Human Urinary Bladder as a Soft Biological Shell. In: Roustem N. Miftahof, Hong Gil Nam, editors. Biomechanics of the Human Urinary Bladder. Heidelberg: Springer-Verlag Berlin Heidelberg; 2013:147-61.

93. Chapter 6 Unsteady flow and nonuniform geometric models. In: Chandran KB, Rittgers SE, Yoganathan AP. editors. Biofluid Mechanics: The Human Circulation. Boca Raton: CRC Press; 2006:191-256.

94. Jones SM, Yerly J, Hu Y, et al. Structure of Proteus mirabilis biofilms grown in artificial urine and standard laboratory media. FEMS Microbiol Lett 2007;268:16-21.

95. Wasfi R, Hamed SM, Amer MA, et al. Proteus mirabilis Biofilm: Development and Therapeutic Strategies. Front Cell Infect Microbiol 2020;10:414.

96. Sousa C, Teixeira P, Oliveira R. Influence of Surface Properties on the Adhesion of Staphylococcus epidermidis to Acrylic and Silicone. Int J Biomater 2009;2009:718017.

Cite this article as: Xiong $\mathrm{GB}$, Xie $\mathrm{SH}$, Liu $\mathrm{AB}$. In vitro dynamic bladder models for studying urinary tract infections: a narrative review. Ann Palliat Med 2021;10(4):4830-4839. doi: 10.21037/apm-20-2061
97. Song F, Koo H, Ren D. Effects of Material Properties on Bacterial Adhesion and Biofilm Formation. J Dent Res 2015;94:1027-34.

98. Carniello V, Peterson BW, van der Mei HC, et al. Physicochemistry from initial bacterial adhesion to surfaceprogrammed biofilm growth. Adv Colloid Interface Sci 2018;261:1-14.

99. Chutipongtanate S, Thongboonkerd V. Systematic comparisons of artificial urine formulas for in vitro cellular study. Anal Biochem 2010;402:110-2.

100. Lebeaux D, ChauhanA, Rendueles O, et al. From in vitro to in vivo models of bacterial biofilm-related infections. Pathogens 2013;2:288-356.

101.Jiang ZL, Fan YB, editors. Biomechanics: from Foundation to Frontier. Beijing: Science Press; 2010:1-220.

102. Rittmann BE, Boltz JP, Brockmann D, et al. A framework for good biofilm reactor modeling practice (GBRMP). Water Sci Technol 2018;77:1149-64.

103.Xiong GB, Liu AB, Wang SZ, et al. Urine turbulent shear stress system of bionic human bladder based on bacterial biofilm reactor: in vitro construction. Chinese Journal of Tissue Engineering Research 2021;25:1560-5.

(English Language Editor: A. Kassem and J. Chapnick) 
Supplementary

Table S1 Data of bladder model comparison

\begin{tabular}{|c|c|c|c|}
\hline First author & Year & Model & Outcome \\
\hline \multirow[t]{2}{*}{ Frant M (20) } & 2018 & Encrustator ${ }^{\circledR}$ Model & $\begin{array}{l}\text { Only a small amount of crystal deposit }\left(\sim 0.057 \mathrm{mg} / \mathrm{cm}^{2}\right) \text { formed on the surface of } \\
\text { the polyurethane catheter, and the main components were magnesium ion and } \\
\text { phosphate; only a small amount of calcium, potassium, sodium and oxalate ion were } \\
\text { detected. }\end{array}$ \\
\hline & & BioEncrustation Model & $\begin{array}{l}\text { A significantly higher concentration of sediment }(\sim 0.37 \mathrm{mg} / \mathrm{cm} 2) \text { formed, which } \\
\text { was mainly composed of sodium and oxalate ions. In addition, a large number of } \\
\text { divalent cationic magnesium and calcium were detected. The surface phosphate ion } \\
\text { concentration is comparable. }\end{array}$ \\
\hline $\begin{array}{l}\text { Azevedo AS } \\
(27)\end{array}$ & 2017 & Static model & $\begin{array}{l}\text { The growth curve of the dynamic model is similar to that of the two bacterial biofilm } \\
\text { formed on the artificial urine silicone test piece in the previous study. Fish combined } \\
\text { with CLSM to evaluate the spatial distribution of biofilm. Compared with the dynamic } \\
\text { condition, the single species biofilm in the static condition has a higher thickness } \\
\text { value }\end{array}$ \\
\hline \multirow[t]{2}{*}{ Ivanova K (30) } & 2015 & Static model & $\begin{array}{l}\text { Foley catheter coated with acylase in the dynamic system has the same trend of } \\
\text { inhibiting biofilm formation as that in the static system }\end{array}$ \\
\hline & & Dynamic model & $\begin{array}{l}\text { Crystal violet and fluorescence image analysis showed that the formation of acylase } \\
\text { coated bacterial biofilm was inhibited by } 80 \% \text { when Pseudomonas aeruginosa } \\
\text { ATCC } 10145 \text { was infected in a dynamic environment. }\end{array}$ \\
\hline $\begin{array}{l}\text { Rasmussen } \\
\text { A (56) }\end{array}$ & 1996 & $\begin{array}{l}\text { Bladder model with no } \\
\text { urine flow meter }\end{array}$ & The bacteria were positive after three days of culture. \\
\hline
\end{tabular}

